\title{
Atık Polietilen Tereftalat (PET) ile Modifiye Edilmiş Saf Bitümün Fiziksel, Morfolojik ve Isıl Özellikleri
}

\author{
Tacettin GEÇKILL ${ }^{1}$, Yunus ÖNAL ${ }^{2}$, Ceren Beyza INCE ${ }^{3 *}$ \\ ${ }^{1}$ İnşaat Mühendisliği Bölümü, Mühendislik Fakültesi, İnönü Üniversitesi, Malatya, Türkiye \\ ${ }^{2}$ Kimya Mühendisliği Bölümü, Mühendislik Fakültesi, İnönü Üniversitesi, Malatya, Türkiye \\ 3*İnşaat Mühendisliği Bölümü, Mühendislik Fakültesi, İnönü Üniversitesi, Malatya, Türkiye \\ ${ }^{1}$ tacettin.geckil@inonu.edu.tr, ${ }^{2}$ yunus.onal@inonu.edu.tr, ${ }^{3 *}$ c.beyzaince@gmail.com
}

Öz: Bu çalışmada, atık PET ile modifiye edilmiş bir bitümün fiziksel, morfolojik ve 1sıl özelliklerindeki değişimler incelenmiştir. Çalışmada, bitüm ile PET arasında iyi bir etkileşim sağlamak amacıyla Trietanolamin (TEO) kimyasal katkısı kullanılmıştır. Bu amaçla, B 70/100 penetrasyon sınıfına sahip bitüme ilk olarak bitümün ağırlıça \%2,5 TEO ilave edilmiştir. Daha sonra, bitüm+TEO karışımına bitümün ağırlıkça \%2, 4, 6, 8 ve 10 oranlarında PET ilave edilerek modifiye bitümler elde edilmiştir. Saf ve modifiye bitümlerin özellikleri, penetrasyon, yumuşama noktası, düktilite, kütle kaybı, Taramalı elektron mikroskobu (SEM) ve X-1şını kırınımı (XRD) deneyleri ile belirlenmiştir. Ayrıca, bitümlerin penetrasyon indeksi (PI) değerleri de belirlenmiștir. Test sonuçlarına göre; katkı miktarının artışı ile modifiye bitümlerin, saf bağlayıcıya göre penetrasyon ve düktilite değerlerinde belirli bir yüzdeye kadar (\%6 PET) düzenli bir azalma, daha sonra artı̧̧; yumuşama noktası değerlerinde ise bu yüzdeye kadar artış, daha sonra azalma meydana gelmiştir. SEM görüntüleri ve XRD grafikleri, PET ile bitümün kimyasal bir bağ oluşturarak iyi bir etkileşim içerisine girdiğini ve karışımın homojen tek fazlı bir yapı gibi davrandığını göstermiştir. Sonuç olarak, \%6 PET oranında bitüm kıvamının daha sert hale geldiği ve sınıfının değiştiği (B 50/70), tekerlek izi direnci bakımından bu oranın uygun olduğu, ancak PI bakımından \%4 PET oranının daha uygun olduğu görülmüştür.

Anahtar kelimeler: Bitüm, atık PET, Trietanolamin, SEM, XRD.

\section{Physical, Morphological and Thermal Properties of Pure Bitumen Modified with Waste Polyethylene Terephthalate (PET)}

\begin{abstract}
In this study, the changes in the physical, morphological and thermal properties of a bitumen modified with waste PET were investigated. In the study, Triethanolamine (TEO) chemical contribution was used to provide a good interaction between bitumen and PET. For this purpose, $2.5 \%$ TEO by weight of bitumen was first added to bitumen having penetration class of B 70/100. Then, 2, 4, 6, 8 and 10\% PET by weight of the bitumen was added to bitumen+TEO blend and modified bitumens were obtained. The properties of pure and modified bitumens were determined by penetration, softening point, ductility, mass loss, scanning electron microscopy (SEM) and X-ray diffraction (XRD) experiments. In addition, the penetration index (PI) values of bitumen were determined. According to the test results; with the increase in the amount of additive, there was a regular decrease in the penetration and ductility values $(6 \%$ PET) of the modified bitumens compared to the pure binder, then an increase; however, in the softening point values increased up to this percentage and then decreased. SEM images and XRD graphs showed that PET and bitumen interact well by forming a chemical bond, and that the mixture acts as a homogeneous single-phase structure. As a result, it was found that the bitumen consistency became more solid and its class changed (B 50/70) at 6\% PET, this ratio was suitable for permanent deformation resistance, but $4 \%$ PET was more suitable for PI
\end{abstract}

Key words: Bitumen, waste PET, Triethanolamine, SEM, XRD.

\section{Giriș}

Bitümlü sıcak karışım (BSK) kaplamalar agrega ve bitüm olmak üzere başlıca iki ana malzemeden oluşur ve her iki malzemenin özellikleri de kaplamanın performansını doğrudan etkilemektedir. BSK'ların ağırlıça \%5-7'sini, hacimce \%13-15'ini oluşturan bitümler, agrega daneleri ile birleştiğinde birbirine bağlanarak ve düzgün kaplama yüzeyi oluşturarak yük altındaki kaplamanın dağılmasını önler, sürüş konforu sağlar ve karışımın boşluklarını doldurarak geçirimsizliği sağlarlar [1,2]. İlk inşa edildiklerinde yüksek performans

\footnotetext{
* Sorumlu yazar: c.beyzaince@ gmail.com . Yazarlarm ORCID Numaras1: ${ }^{1}$ 0000-0001-8070-6836, ${ }^{2}$ 0000-0001-6342-6816, ${ }^{3 *} 0000-0002-$ 6385-0964
} 
gösteren BSK kaplamalarda, trafik, iklim ve çevre şartları etkisiyle zamanla kalıcı deformasyon, düşük sıcaklık çatlakları, soyulmalar ve yorulma çatlağı gibi bozulmalar meydana gelmektedir [3,4]. Kaplamayı olumsuz yönde etkileyen bu bozulmalara karşı bitüme ya da karışıma çeşitli katkı maddeleri eklenerek modifiye bitüm veya karışımlar elde edilmektedir. Modifikasyon işlemi ile daha uzun hizmet ömrüne sahip, stabilitesi yüksek, deformasyonlara karşı daha dirençli kaplamaların yapılması amaçlanmaktadır. Günümüzde modifikasyon için çoğunlukla polimerler olmak üzere kauçuk, siyah karbon, çeşitli yağlar, filler malzemeler, elyaflar ve çeşitli çözücüler gibi bazı katkılar kullanılmaktadır [1]. Polimer gruplarında en çok kullanılanlar ise düşük yoğunluklu polietilen (DYPE), yüksek yoğunluklu polietilen (YYPE), polietilen tereftalat (PET/PETE), polipropilen (PP), polivinil klorid (PVC), Stiren-Butadien-Stiren (SBS), polistiren (PS) ve etilen vinil asetat (EVA) sayılabilir [5,6]. Bu polimerler cinslerine göre bitüm veya bitümlü karışımların farklı bazı özelliklerini iyileştirmek için sıkça kullanılmaktadır [5-7].

$\mathrm{Bu}$ çalıșmada bitümün ve dolayısıyla esnek kaplamanın performansını geliștirmek ve çevreye vermiș olduğu zararı en aza indirgemek amacıyla bitüm modifikasyonunda atık PET kullanılmıştır.

Polietilen tereftalat (PET), dünya genelinde iplik, şişe, fotoğraf filmi, lastik kablo, emniyet kemeri, gıda ambalajları, saklama kapları vb. birçok alanda kullanılmaktadır. PET, doğada kendi kendine ayrışamayan, geri dönüşüm sayesinde tekrar kullanılabilen bir malzemedir [8]. PET kaynaklı atıklar, dünyadaki katı atık miktarının ağırlıkça \%8 'ini ve hacimce $\% 12$ 'sini oluşturmaktadır. Türkiye'de yıllık 165 bin ton pet şişe üretilmektedir ve bunun sadece 40 bin tonu geri dönüşüme uğramaktadır. Her yıl doğaya karışan 125 bin ton pet şişenin maliyeti ortalama 70 milyar dolardır. Atıkların değerlendirilmesi konusunda geri dönüşüme yeterince önem verilmesi hem maliyet açısından; hem de çevre kirliliğinin önüne geçilmesi açısından ülkemize önemli faydalar sağlayacaktır [9].

Asfalt karışımlarda PET kullanılarak yapılan birçok çalışmada, PET’in kalıcı deformasyon azalma, yorulmaya karşı direnç ve stabilite de artma, ayrıca yol maliyetinde önemli faydalar sağlayacağı görülmüştür [10-12]. Atık veya geri kazanılmış PET şişelerin uygun oranlarda agrega yerine kullanılarak yapılan bir çalışmada PET'in belirli bir noktada kalıcı deformasyonunun maksimuma ulaştı̆ıı ayrıca PET' in agrega yerine kullanılmasıyla yol maliyetinin önemli derecede düşeceği sonucuna varılmışır [13]. Başka bir çalışmada atı19PET katkılı karışımların, karışım özelliklerini iyileştirdiği fakat bunun boyut ile alakalı olduğu sonucuna varılmıştır [14]. Atık PET elyaf kullanılarak yapılan bir çalışmada, kaplamanın yorulma ömrünün iyileștiği sonucuna varılmıştır [15]. PET' ten üretilen şişelerin çevreyi çok kirlettiği ve fazla alan kapladığı düşüncesinden çıkarak asfalt karışımlarda kaba agrega yerine PET kullanılan çalışmada ise PET kullanımının karışımdaki yüzdesinin ilk olarak stabiliteyi iyileştirdiği fakat belirli yüzdeden sonra düşürdüğü sonucuna varılmıştır [16]. Asfalt modifikasyonunda PET kullanılarak yapılan çalışmalarda, PET modifiyeli bağlayıııların penetrasyon değerinde azalma, yumuşama noktası ve viskozite değerlerinde önemli artışlar meydana geldiği tespit edilmiştir. Ayrıca PET katkısının yüksek sıcaklık performansını artırdığı, kaplamayı daha sert bir kıvama getirdiği sonucuna varılmıștır $[17,18]$. Devulkanize PET kullanılarak yapılan bir çalıșmada, katkılı bağlayıcıların saf bağlayıcılara göre penetrasyon değerinde azalma, yumuşama noktası ve viskozite değerlerinde artışlar meydana gelmiştir. Ancak, yüksek sıcaklıklardaki depolama stabilitesi testi sonucunda ise tüm PET katkılı bağlayıcıların modifiye bitüm şartname sınırlarına uymadığı ve depolamada kararlı bir karışım olmayacağı sonucuna varılmıștır [19]. Başka bir çalıșmada ise asfalta PET ilavesinin penetrasyonu azalttığı, yumuşama noktası ve viskoziteyi artırdığı ayrıca yaşlanmaya karşı da dirençli olabileceği sonucuna varılmıştır [20]. Atık PET kullanılarak yapılan diğer bir çalışmada, PET malzeme oranının artmasıyla; penetrasyon değerinde bir azalış, yumuşama noktası değerinde ise bir artış gözlemlenmiştir. Ayrıca bu durumun karışımın sertlik ve kıvamını artırarak, karışımı kalıcı deformasyonlara karşı daha dayanıklı hale getirdiği ve sıcak iklimli bölgelerinde kaplama tabakalarında kullanılabileceği sonucuna varılmıştır [21].

Son yıllarda bitüm modifikasyonunda sıklıkla doğal ve atık polimerler yoğun bir şekilde kullanılmalarına ve bunların modifiye bitümlerin birçok özelliklerini olumlu yönde etkilemelerine rağmen bazı olumsuzlar oluşturdukları da görülmüștür. Bunlardan en önemlisinin yüksek sıcaklıklardaki depolama stabilitesi olduğu bilinmektedir. Çalışmalarda bu durumun, bu tür polimerlerin bitüm içerisinde fiziksel olarak homojen dağılabildiğini ancak yüksek sıcaklıklardaki depolama esnasında polimerlerin özelliklerine göre ya dibe çöktüğ̈̈ ya da yüzeye çıktığı dolayısıyla bu homojen yapının bozulduğu görülmüştür. Bu durum, araştırmacıları bitüm ile kimyasal reaksiyon olușturabilen polimerlere (reaktif terpolimerler) veya polimer ile asfalt arasında kimyasal reaksiyon oluşturabilen çeşitli katkılara yönlendirmiştir [22,23].

$\mathrm{Bu}$ çalışmada, bitüm atık PET ile modifiye edilerek bitümün dolayısıyla BSK' nın özelliklerinin iyileştirilmesi amaçlanmıştır. Bu amaçla, PET'in bitüm ile kimyasal reaksiyonunu sağlamak ve bitüm içerisinde homojen bir dağılım elde etmek amacıyla daha önce hiçbir çalışmada kullanılmamış olan TEO kullanılmıştır. 
Çalışmada, bu şekilde kullanılan atık PET'in bitümün fiziksel ve kimyasal özellikleri üzerindeki etkileri penetrasyon, yumuşama noktası, düktülite, kütle kaybı, SEM ve XRD deneyleri ile belirlenmeye çalışılmıştır.

\section{Materyal ve Yöntem}

Bu çalışmada, Elazığ Karayolları 8. Bölge Müdürlüğü asfalt şantiyesinden temin edilen B 70/100 penetrasyon sınıfı bitüm kullanılmıştır. B 70/100 bitümünün fiziksel özellikleri Tablo 1 de verilmiştir.

Tablo 1. B 70/100 bitümünün fiziksel özellikleri

\begin{tabular}{|c|c|c|c|}
\hline \multirow{2}{*}{ Deneyler } & \multirow{2}{*}{ Deney Standardı } & \multicolumn{2}{|c|}{ B 70/100 } \\
\cline { 3 - 4 } & & Şartname Limitleri & Ölçülen Değer \\
\hline Penetrasyon $(0,1 \mathrm{~mm})$ & TS EN 1426 & $70-100$ & 88 \\
\hline Yumuşama Noktası $\left({ }^{\circ} \mathrm{C}\right)$ & TS EN 1427 & $43-51$ & 46,75 \\
\hline Düktilite $(\mathrm{cm})$ & TS 119 & $\operatorname{min~} 100$ & $>100$ \\
\hline Parlama Noktası $\left({ }^{\circ} \mathrm{C}\right)$ & EN 22719 & $\min 230$ & 238 \\
\hline Özgül Ağırlık $\left(\mathrm{gr} / \mathrm{cm}^{3}\right)$ & TS 1087 & $1,0-1,1$ & 1,038 \\
\hline
\end{tabular}

Katkı malzemesi olarak kullanılan PET, Adana Meltem Kimya Ltd.Şti. tarafından temin edilmiştir. PET’ in genel özellikleri Tablo 2 de belirtilmiştir.

Tablo 2. PET'in genel özellikleri [12]

\begin{tabular}{|c|c|}
\hline ÖZELLİK & POLIETiLEN TEREFTALAT (PET) \\
\hline Yoğunluk $(\mathrm{gr} / \mathrm{ml})$ & $1,33-1,38 \mathrm{gr} / \mathrm{ml}$ \\
\hline Kullanılabilir Max. Sıcaklık $\left({ }^{\circ} \mathrm{C}\right)$ & $60{ }^{\circ} \mathrm{C}$ \\
\hline Sertlik Derecesi & Orta \\
\hline Renk & Açık renkli \\
\hline Erime Sicaklığ $\left({ }^{\circ} \mathrm{C}\right)$ & $250{ }^{\circ} \mathrm{C}$ \\
\hline Kalorifik Değeri $(\mathrm{Kkal} / \mathrm{kg})$ & $11060 \mathrm{Kkal} / \mathrm{kg}$ \\
\hline Tane Boyutu $(\max )$. & $0,3 \mathrm{~mm}$ \\
\hline
\end{tabular}

Bitüm ile PET arasında kimyasal bir bağ oluşturmak için kimya mühendisliği laboratuvarından temin edilmiş olan Trietanolamin (TEO) kullanılmıştır. TEO $\left(\mathrm{C}_{6} \mathrm{H}_{15} \mathrm{NO}_{3}\right)^{\prime}$ nun kimyasal özellikleri Tablo 3 de belirtilmiştir.

Tablo 3. Trietanolamin $\left(\mathrm{C}_{6} \mathrm{H}_{15} \mathrm{NO}_{3}\right)^{\prime}$ in kimyasal özellikleri [24]

\begin{tabular}{|c|c|}
\hline ÖZELLİ & TRİETANOLAMIN (TEO) \\
\hline Kimyasal formül & $\mathrm{C}_{6} \mathrm{H}_{15} \mathrm{NO}_{3}$ \\
\hline Molar kütle $(\mathrm{g} / \mathrm{mol})$ & $149,19 \mathrm{~g} / \mathrm{mol}$ \\
\hline Kaynama noktası $\left({ }^{\circ} \mathrm{C}\right)$ & $335,4{ }^{\circ} \mathrm{C}$ \\
\hline Yoğunluk $\left(\mathrm{g} / \mathrm{cm}^{3}\right)$ & $1,12 \mathrm{~g} / \mathrm{cm}^{3}$ \\
\hline Yapı & Bazik \\
\hline
\end{tabular}

Çalışmada, modifiye bitümler elde etmek amacıyla saf bitüm $160{ }^{\circ} \mathrm{C}$ sıcaklığa kadar 1 sıtılmış ve bitüm ağırlığının \%2,5‘i kadar TEO ilave edilerek aynı sıcaklıkta 500 devirde 10 dakika boyunca karıştırma işlemi devam ettirilmiştir. Kullanılan bu oran, devir ve karıştırma süresi, literatürde benzer çalışmalar bulunmadığından laboratuvarda yapılan ön çalışmalar neticesinde belirlenmiştir. Daha sonra her bir yüzde için aynı işlem sırası 
takip edilerek, ardından bitüm ağırlığının \%2, 4, 6, 8 ve 10 oranlarında PET ilavesi edilmiş ve karıştırma işlemi 1000 devirde 30 dakika boyunca aynı sıcaklıkta devam ettirilmiştir. Çalışmada kullanılan karıştırma cihazı ve yapılan modifikasyon işlemi Şekil 1'de gösterilmiştir.
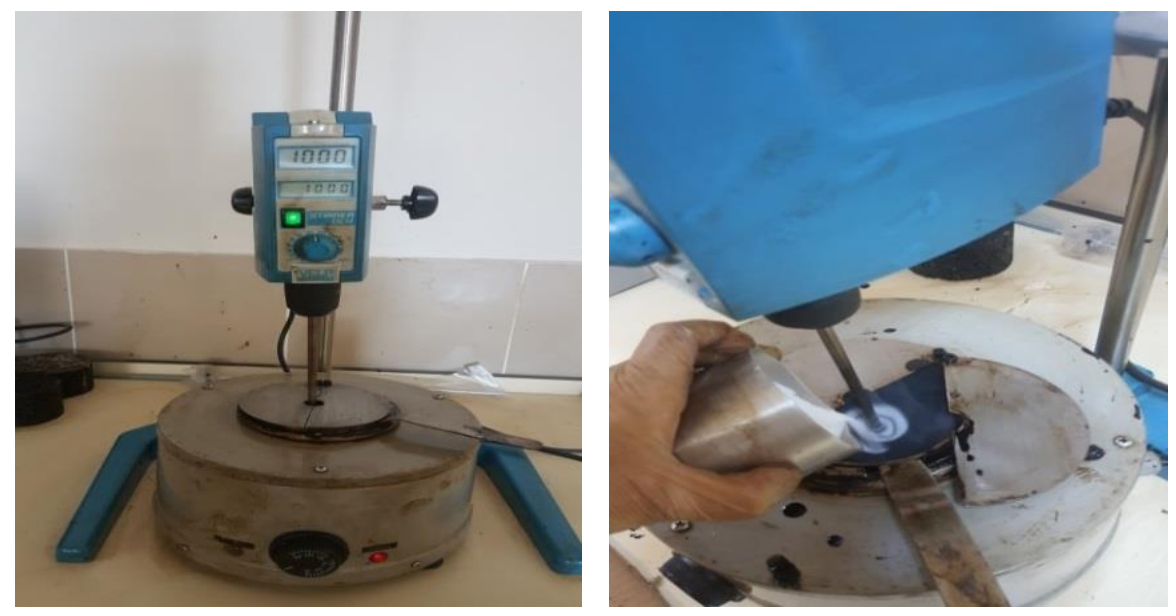

Şekil 1. Karıştırma cihazı (a) ve bitüme PET eklenmesi (b)

Çalışmada elde edilmiş olan saf ve modifiye bitümler sırasıyla $\mathrm{B}, \mathrm{B}+\% 2 \mathrm{PET}, \mathrm{B}+\% 4 \mathrm{PET}, \mathrm{B}+\%$ PET, $\mathrm{B}+\% 8 \mathrm{PET}$ ve $\mathrm{B}+\% 10 \mathrm{PET}$ olarak kodlanmıştır. Saf ve modifiye bağlayıcılar fiziksel ve kimyasal deneylere tabi tutulmuş ve 1 sıl özellikleri tespit edilmiştir.

\subsection{Bağlayıcıların fiziksel özelliklerinin tayini}

Elde edilmiş olan saf ve modifiye bitümlerin fiziksel özellikleri TS EN 1426, TS EN 1427 ve TS EN 12589 standartlarına göre sırasıyla penetrasyon, yumuşama noktası ve düktilite deneyleri ile belirlenmiştir.

Bağlayıcılarda oluşan kütle kaybı ise, ASTM D 2872 standardına göre dönel ince film etüvü deneyi (RTFOT) ile tespit edilmiştir. RTFOT deneyinde, asfalt numunesi üzerinde kısa süreli yaşlandırma yapılarak numune üzerinde sicaklık ve hava etkisiyle meydana gelen uçucu madde kaybının belirlenebilmesi için yapılmaktadır. Kütle kaybı, ilk kütle ile son kütle arasındaki farkın ilk kütleye bölünmesi ile elde edilmektedir $[25,26]$.

\subsection{Bağlayıcıların kimyasal (morfolojik) özelliklerinin tayini}

Saf ve modifiye bağlayıcıların kimyasal özellikleri X-Işını Kırınımı (XRD) ve Taramalı Elektron Mikroskobu (SEM) deneyleri ile belirlenmiştir.

XRD, katı malzemelerdeki kristal fazları tanımlamak ve bu fazların yapısal özelliklerini analiz etmek için kullanılan çok yönlü bir analiz yöntemidir. Modifiye bitümlerin kristalit parametreleri yaygın olarak XRD ile belirlenir. Bitümlü bağlayıcının yapısal parametrelerinin pik yoğunluğuna ve konumuna göre niceliksel yoğunluk eğrileri elde edilir. SEM, malzemelerin mikro-morfolojik yapısının gözlemlenmesi ve analiz yapılmasını sağlayan karakterizasyon aracıdır. SEM, malzemenin yapısının ve homojenliğinin izlenmesine izin verdiği için polimer modifiyeli bitümün faz morfolojisini incelemede önemli bir yöntemdir. SEM görüntüleri; bitüm-polimer uyumluluğunun anlaşılmasını sağlamada ve yaşlanma sürecinden kaynaklanan hasarı ortaya çıkarmada kullanılmaktadır. Bu görüntülerde bitüm bakımından zengin olan faz koyu veya siyah görülürken polimer faz açık renkte görülmektedir [27].

\subsection{Bağlayıcıların sıcaklık hassasiyeti (PI)}

Bitümlü bağlayıcıların ısıya karşı duyarlılığının tespit edilmesinde çoğunlukla Penetrasyon İndeksi (PI) değeri kullanılmaktadır. PI değeri Denklem 1 ve Denklem 2 yardımıyla hesaplanmıştır. 


$$
\begin{gathered}
A=\frac{\log 800-\log P_{25}}{T_{Y N}-25} \\
P I=\frac{20-500 A}{1+50 A}
\end{gathered}
$$

Formüldeki $P_{25}$, bitümün $25^{\circ} \mathrm{C}$ sıcaklıktaki penetrasyon değerini, $T_{\mathrm{YN}}$ ise yumuşama noktası değerini belirtmektedir. PI değerinin -2'den küçük olması bitümün 1sıya çok duyarlı olduğunu, +2' den büyük olması ise 1sıya karşı duyarlı olduğunu göstermektedir [28].

\section{Bulgular ve Değerlendirme}

\subsection{Bitümlerin fiziksel özellik sonuçları}

Bitümlerin TS EN 1426’ya göre yapılan penetrasyon deney sonuçları Şekil 2 de gösterilmiştir.

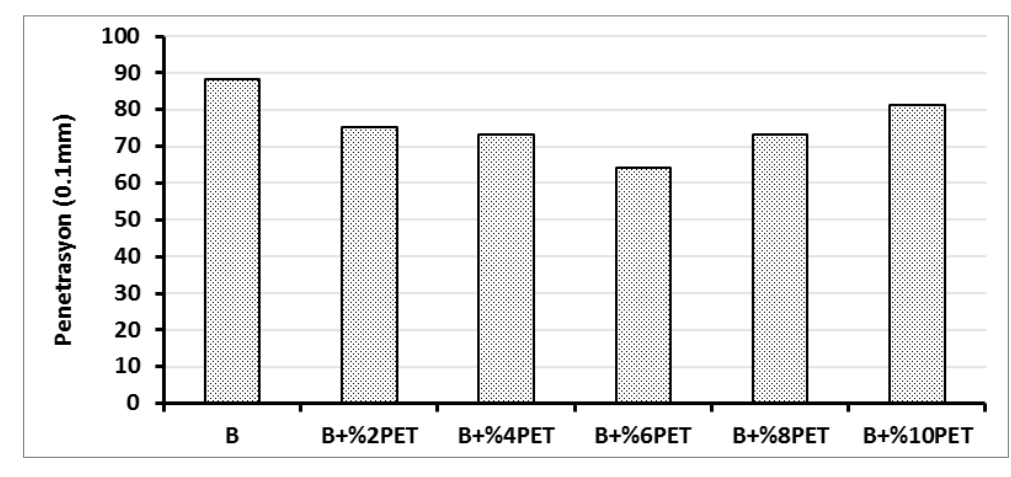

Şekil 2. Saf ve modifiye bitümlerin penetrasyon değişimleri

Şekil 2'de görüldüğü gibi B 70/100 saf bitümüne PET eklenmesiyle penetrasyon değerlerinde önemli değişimler meydana gelmiştir. Katkı ilavesi ile \%6 PET oranına kadar penetrasyonda önce bir azalma, katkının artmaya devam etmesi ile daha sonra bir artış meydana gelmiştir. Bu değişimler saf bitüme göre sırasıyla \%14,8; $\% 17 ; 27,3 ; \% 17$ ve \% 8 azalış olarak tespit edilmiştir. Bu durum PET ilavesi ile modifiye bitümün önce sertleşmeye başladığını ancak daha sonra tekrar yumuşamaya başladığını göstermektedir. Bu sertleşme veya penetrasyon değerindeki azalma sonucunda \%6 PET katkılı modifiye bitümün penetrasyon sınıfı B 50/70 olarak değişmiştir. Bunun sonucu olarak, nispeten daha 1lıman bölgelerde kullanılabilen B 70/100 asfalt bağlayıcısının \%6 PET ilave edilmesiyle çok daha sıcak bölgelerde kullanılabileceğini ve bunun bitümden kaynaklı kalıcı deformasyonlara karşı daha elverişli olduğunu ifade etmek mümkündür.

Bitümlerin TS EN 1427'ye göre yapılan yumuşama noktası deney sonuçları Şekil 3'de gösterilmiştir. Şekil 3'te görüldüğü gibi B 70/100 saf bitümüne PET eklenmesiyle yumuşama noktası değerinde önemli değişimler meydana gelmiştir. Katkı miktarının artışına bağlı olarak bu değişim oranları saf bitüme göre sırasıyla \%8,7; $\% 9,3 ; \% 11,7 ; \% 7,5$ ve \%3,5 artış olarak tespit edilmiştir. PET modifiyeli bitümlerde katkı oranı arttıkça yumuşama noktası değeri \%6'ya kadar artış gösterip, daha sonra azalma eğilimi göstermiştir. Bu karışımlarda en yüksek yumuşama noktası değerine ise \%6 PET oranında ulaşılmıştır. Yumuşama noktası deney sonuçları penetrasyon sonuçları ile paralellik arz etmektedir. Yani bağlayıcılar önce sert bir kıvama gelmiş daha sonra tekrar yumuşama eğilimine girmiştir. Düşük penetrasyon ve yüksek yumuşama noktası değerleri, \%6 PET ilavesinin bağlayıcının sıcaklık hassasiyetini azalttığını ve daha sıcak bölgelerde kullanılabileceğini göstermektedir. 


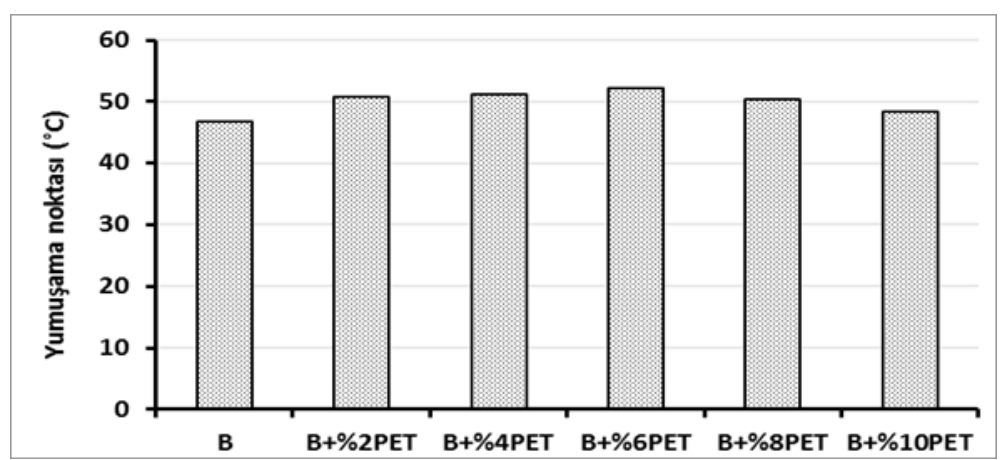

Şekil 3. Saf ve modifiye bitümlerin yumuşama noktası değişimleri

Bitümlerin TS EN 12589 standardına göre yapılan düktilite deney sonuçları Şekil 4'de gösterilmiştir.

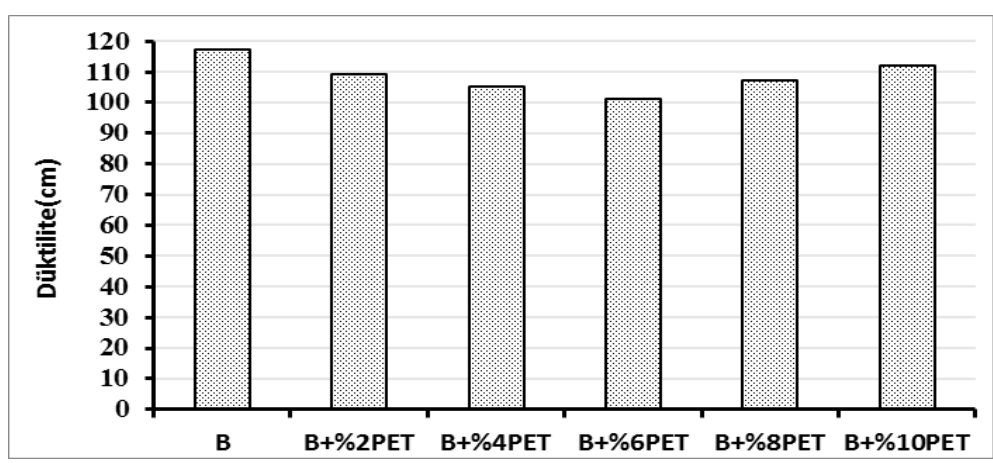

Şekil 4. Saf ve modifiye bitümlerin düktilite değişimleri

Şekil 4'de görüldüğü gibi B 70/100 saf bitümüne PET eklenmesiyle düktilite değerlerinde önemli değişimler meydana gelmiştir. Katkı ilavesine bağlı olarak, bu değişim oranları saf bitüme göre sırasıyla \%6,8; \%10,3; $\% 13,7 ; \% 8,5$ ve \%4,3 azalma şeklinde gerçekleşmiştir. PET ilavesiyle modifiye bitümlerin düktilite değerlerinde \%6'ya kadar bir azalma, daha sonra ise artış meydana gelmiştir. Bağlayıcı kıvamı bakımından, düktilite sonuçları penetrasyon ve yumuşama noktası sonuçları ile paralellik göstermiştir. Düktilite değerindeki azalma, bitümlü bağlayıcının uzama kabiliyetinin ve kohezyon mukavemetinin düşmesi, artması ise bu özelliklerde oluşan artış anlamina gelmektedir.

Saf ve PET ile modifiye edilmiş bitümler üzerinde yapılan RTFOT deneyi sonucu oluşan kütle kayıpları hesabı için, bağlayıcılar $160{ }^{\circ} \mathrm{C}$ 'de ısıtılarak 8 adet şişeye, her birine 35 gr. bağlayıcı eklenerek $163{ }^{\circ} \mathrm{C}$ sıcaklıkta ve 75 dakika süreyle gerçekleştirilmiştir. Deney sonucunda saf ve PET ile modifiye edilmiş bitümlerin kütle kayıpları tespit edilmiş ve katkı oranı değişimi ile kütle kaybı arasındaki ilişki Şekil 5 de gösterilmiştir.

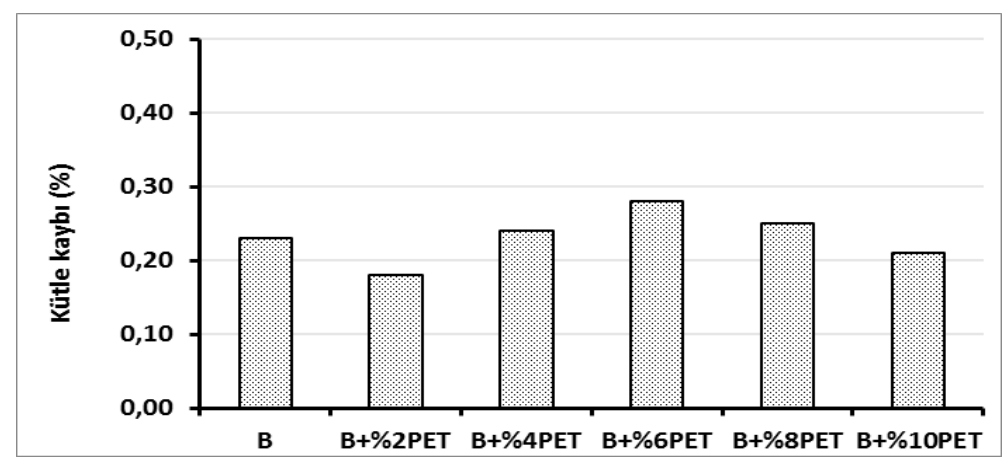

Şekil 5. Saf ve modifiye bitümlerin kütle kaybı değişimleri 
Şekil 5'de görüldüğü gibi B 70/100 saf bitümüne PET eklenmesiyle kütle kayıplarında değişimler meydana gelmiştir. Saf ve modifiye bağlayıcıların kütle kaybı değerleri sırasıyla $\% 0,23 ; 0,18 ; 0,24 ; 0,28 ; 0,25$ ve 0,21 olarak şartname limitlerinin oldukça altında elde edilmiştir. Bu değişim oranı saf bitüme göre sırasıyla \%22 azalma; \%4,3; \%21,7 ve \%8,7 artış ve \%9 azalma şeklinde gerçekleşmiştir. Bu sonuçlara göre, saf ve modifiye bağlayıcıların ısıtılma, taşınma, depolanma ve kaplama inşası esnasında ciddi sertleşme göstermeyeceğini ve elastikiyetini kaybetmeyeceğini ifade etmek mümkündür. Ayrıca, bağlayıcıların sıcaklık ve oksidasyona karşı yeterince dirençli oldukları da belirtilebilir.

\subsection{Bağlayıcıların kimyasal özellik sonuçları}

Saf ve PET ile modifiye edilmiş bitümlerin morfolojisi, XRD karakterizasyon teknikleri kullanılarak belirlendi. X 1 șını kırınım desenleri, $\mathrm{CuK} \alpha$ radyasyonuna sahip bir Rigaku Giegerflex D-Max/B toz difraktometresi ile elde edilmiştir. Kırınım desenleri $\left(2 \theta=2-80^{\circ}\right)$ oda sıcaklığında $0.02^{\circ}$ 'lik bir adımla kaydedilmiştir. PET' in kristallografik yapısı, asfalt bağlayıcı harmanındaki varlı̆̆ı ve dağılma seviyesi, desenler kullanılarak değerlendirilmiştir.

Çalıșmada yapılmıș olan fiziksel deney sonuçlarına göre en önemli sonuçlar \%6 PET içeren modifiye karışımlardan elde edildiği için sadece bu karışımın XRD deseni verilmiştir. Saf ve \%6 PET modifiyeli bitümlerden elde edilen XRD desenleri, Şekil 6'da verilmiştir.

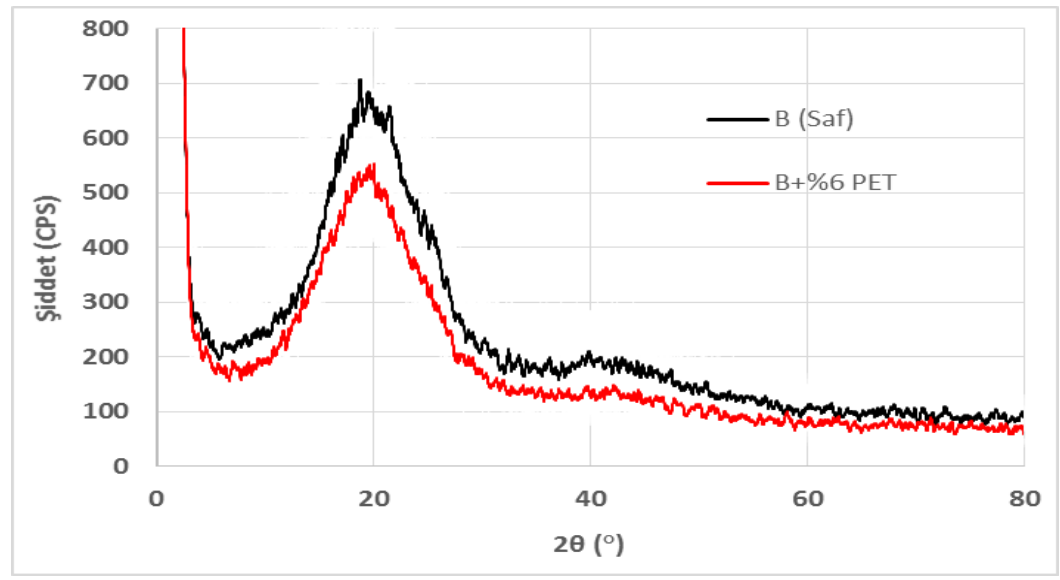

Şekil 6. Saf ve \%6 PET modifiyeli bitümlerin XRD desenleri

Numunelere ait difraktogramlar incelendiğinde (Şekil 6) saf bitüme (B) ait difraktogramı asfalt bağlayıcılar için tipik olup pik maksimumu 20-2 2 geniş ve yayvan ve $43-2 \theta$ değerinde ise geniş ve daha az alana sahip amorf pikler görülmektedir. 20-20'daki geniş pik incelendiğinde kısmen kristalin bölgeler mevcut iken ikinci pik tamamen amorf görülmektedir. B+\%6 PET karışımına ait difraktoğram incelendiğinde 20-2 $\theta$ pik maksimumundaki pik önemli ölçüde azalmış ve kristalin bölgelere ait pikler kısmen kaybolarak amorflaşmanın arttığı görülmektedir. 43-20'daki ikinci amorf pik saf bitüme ait pik ile benzer boyutta çıkmıștır. Bu durum TEO' nun hem bitüm ile hem de PET ile etkileştiği, hatta kimyasal reaksiyona girdiği şeklinde yorumlanabilir. Özellikle TEO' nun bazik yapıda olduğu düşünülürse asidik yapıda olan PET ile önemli ölçüde etkileşebileceği sonucuna varılabilir.

SEM, PET modifiyeli bitümün mikro yapısını araștırmak, PET' in saf bitümdeki dağılım durumunu belirlemek ve sürekli ve süreksiz faz yapısını karakterize etmek için kullanılmıştır. Tüm bağlayıcı numunelerinin yüzey görüntülemesi, 1.0K büyütme ile Zeiss EVO 50 Model cihazı kullanılarak yapılmıştır. Saf ve \%6 PET modifiyeli bitümlerden elde edilen SEM görüntüleri, Şekil 7'de gösterilmiştir.

Saf bitüme ait SEM sonucuna göre yapının oldukça homojen ve grafitik yapıda olduğu görülmektedir. Düzlemsel grafitik yapı nedeniyle kuruma esnasında yapısal gerilmeler sonucu büzülmeler meydana gelmiştir. Büzülmeler arasındaki düzensizlikler yapıda kristalin bölgelerin varlığı ile açıklanabilir. Nitekim XRD difraktogramında saf bitüm büyük oranda amorf karakterde iken kısmen kristalin bölgelerde mevcut idi. $\mathrm{B}+\% 6$ PET karışımında TEO'nın PET ile reaksiyonu ve/veya etkileşimi sonucu grafitik yapı ortaya çıkmaktadır. 
Kurumadan sonraki büzülmenin daha belirgin ortaya çıkması bu etkileşimin gerçekleştiğini doğrulamaktadır. Özellikle kristalin PET ile etkileşme sonucu grafitik yapının ortaya çıkması bitüm ile homojen bir karışım olması ve büzülmenin homojenliği, sonuç ürünün mekaniksel özelliklerini önemli ölçüde artıracağı sonucunu çıkarmaktadır.

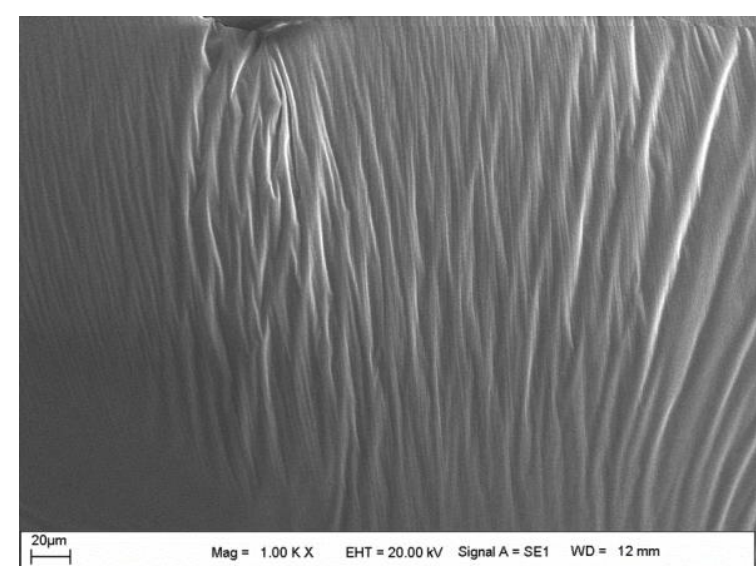

(a)

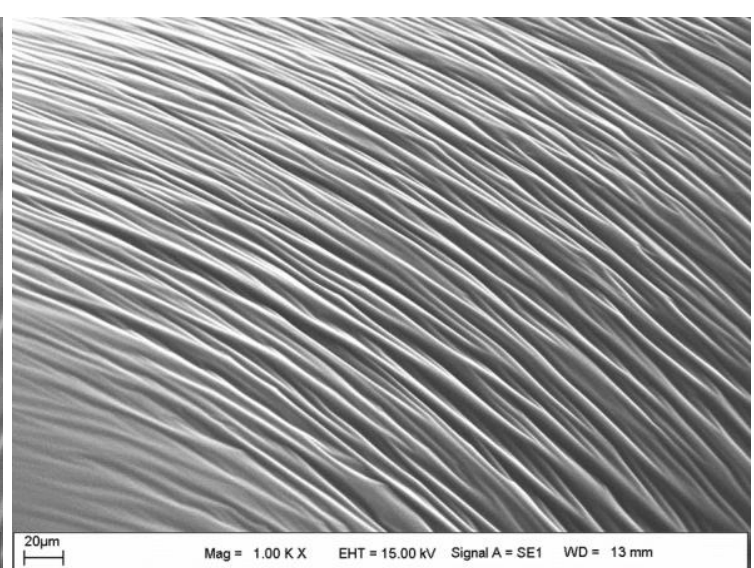

(b)

Şekil 7. Numunelerin SEM görüntüleri: (a) B; (b) B+\%6 PET

\subsection{Bitümlü bağlayıcıların sıcaklık hassasiyeti sonuçları (PI)}

Saf ve modifiye bitümlerin PI değerleri ise formül 2 yardımıyla hesaplanmış olup, sonuçlar Şekil 8 de gösterilmiştir.

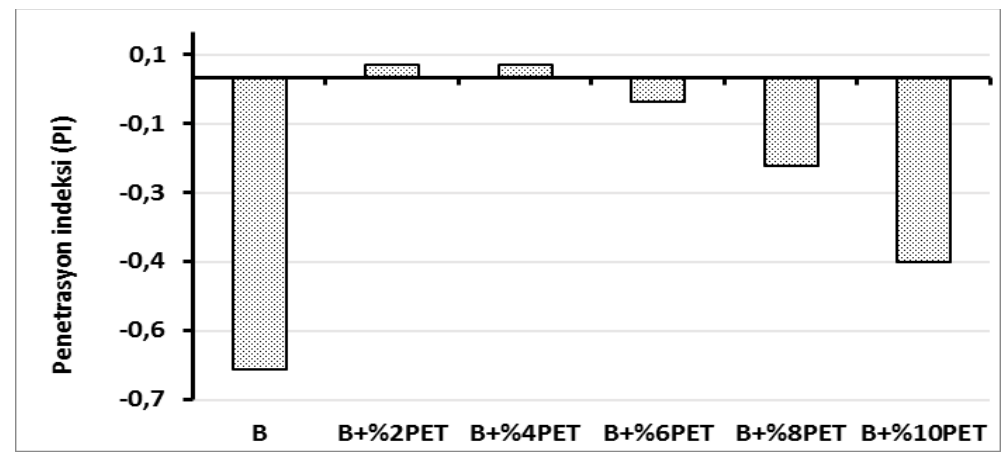

Şekil 8. Saf ve modifiye bitümlerin PI değişimi

Şekil 8'e görüldüğü gibi B 70/100 saf bitüme PET ilavesi ile PI değerlerinde önemli değişimler meydana gelmiştir. Saf ve modifiye bağlayıcıların PI değerleri sırasıyla -0,636;0,026;0,027; -0,054; -0,193 ve $-0,401$ olarak elde edilmiştir. PET ilavesiyle bağlayıcıların sıcaklık hassasiyetlerinin önce düştüğü sonra tekrar yükselme eğiliminde olduğu görülmektedir. Sıcaklık hassasiyeti bakımından en uygun katkı oranının \%4 PET katkılı karışımlar olduğu görülmektedir.

\section{Sonuç ve Öneriler}

Atık PET ve çözücü kimyasal Trietanolamin (TEO) katkısının birlikte kullanılmasının modifiye bitümlerin bazı özelliklerine etkisinin araştırıldığı bu çalışmada elde edilen sonuçlar aşağıda verilmiştir:

Penetrasyon deneyi sonuçlarına göre, bitüme PET ilavesi, başlangıçta bitümü \%6 oranına kadar sertleştirmiş, sonraki oranlarda ise yumuşattığı görülmüştür. \%6 PET ilavesi ile saf bitüm sertleşerek çok daha sıcak bölgelerde kullanılabilecek B 50/70 sınıfına dönüşmüştür. 
Yumuşama noktası sonuçlarının penetrasyon sonuçları ile uyumlu olduğu görülmüştür. \%6 PET ilavesine kadar yumuşama noktası değerleri \%11,7 kadar artmış yani bağlayıcı sertleşmiş, sonra yumuşama noktası değerleri düşmeye başlamıştır. Bu \%6 PET katkılı bağlayıcının yüksek sıcaklığa karşı direncinin artması sebebiyle daha sicak bölgelerde kullanılabileceğini göstermektedir.

Düktilite deneyi sonuçlarına göre, \%6 PET oranına kadar bağlayıcı bünyesinde oluşan sertleşmeden dolayı uzama yeteneğinde azalmalar görülmüş ancak bu orandan sonra artış meydana gelmiştir. En etkili değişim yine \%6 PET katkılı bağlayıcıda meydana gelen \%13,7’lik değişim olmuştur.

Bağlayıcılarda oluşan kütle kaybı en fazla \%6 PET katkılı karışımlarda meydana gelmesine rağmen bütün sonuçlar şartname limitinin oldukça altında çıkmıştır. Bu, elde edilen bağlayıcıların yüksek sıcaklık ve oksidasyona karşı oldukça dirençli olduğunu göstermektedir.

XRD desenleri ve SEM görüntüleri birlikte incelendiğinde, literatürdeki sonuçların aksine PET'in TEO kimyasalının etkisi ile bitümle iyi bir etkileşim veya kimyasal bağ kurarak karışımın homojen tek fazlı bir yapı olmasını sağladığı görülmüştür. Bu durum PET ile modifiye edilen bitümlerin yüksek sıcaklıklarda depolanması esnasında bünyelerinde herhangi bir ayrışma olmayacağı anlamına gelir ki bu da polimer modifiyeli bitümlerde karşılaşılan en büyük sorunlardan birinin ortadan kalkabileceğini ortaya koymaktadır.

PI sonuçlarına göre; PET ilavesi ile bağlayıcıların sıcaklık hassasiyetlerinin \%4 PET oranına kadar düştüğü ancak tekrar yükselmeye başladığını göstermektedir.

Sonuç olarak, bağlayıcıların PET katkısı ile belirli bir orana kadar sertleştiği ancak daha sonra yumuşamaya başladığı, B 70/100 bitümü için bu kritik oranın \%6 olduğu, bu oranda bağlayıcı sınıfının B 50/70 olarak değiştiği ve daha sıcak bölgelerde kullanılabileceği görülmüştür. Çalışmanın en önemli sonucu ise kullanılan kimyasal çözücü ile PET katkısının bitümle kimyasal bir bağ kurarak yüksek sıcaklıklarda depolama esnasında oluşabilecek ayrışma problemini ortadan kaldırdığını ve bu sayede atık PET kullanımının, hem kaplama performansını iyileştirme hem de çevreye vereceği zararı bertaraf etmesi bakımından faydalı olacağını ifade etmek mümkündür.

\section{Kaynaklar}

[1] Tunç A. Yol Malzemeleri ve Uygulamaları. Ankara: Nobel Yayın Dağıtım, 2007.

[2] Lavin PG. Asphalt Pavements. Spon Pres: London and New York, 2003.

[3] Carreau PJ, Bousmina M, Bonniot F. The Viscoelastic Properties of Polymer-Modified Asphalt. The Canadian Journal of Chemical Engineering 2000; 78 (3): 495-502.

[4] Ahmedzade P, Alataş T, Geçkil T. The Effect of Carbon Black On The Mechanical Properties of Asphalt Mixtures. Journal of Engineering and Natural Sciences 2007; 25, 179-189.

[5] Isacsson U, Lu X. Testing and Appraisal of Polymer Modified Road Bitumens-State of the Art, Materials and Structures $1995 ; 28,139-159$.

[6] Iqbal MH. Influence of Polymer Type and Structure on Polymer Modification of Saudi Asphalt. Master of Science Degree, King Fahd University of Petroleum \& Minerals, Dhahran, Saudia Arabia, 2004.

[7] Airey GD. Rheological Properties of Styrene Butadiene Styrene Polymer Modified Road Bitumens, Fuel 2003; 82(14): 1709-1719.

[8] Kalantar Z, Karim M, Mahre, A. A review of using waste and virgin polymer in pavement, Construction and Building Materials 2012; 33: 55-62.

[9] Tayyar E, Üstün S. Geri Kazanılmış Pet'in Kullanımı, Pamukkale Üniversitesi Mühendislik Bilimleri Dergisi 2009; 16(1): 53-62.

[10] Modarres A, Hamedi H. Effect of waste plastic bottles on the stiffness and fatigue properties of modified asphalt mixes, Materials and Design 2014; 61: 8-15.

[11] Moghaddam TB, Soltani M, Karim MR. Evaluation of permanent deformation characteristics of unmodified and Polyethylene Terephthalate modified asphalt mixtures using dynamic creep test, Materials and Design 2014; 53: 317324.

[12] Yaşmun E. Pet Lifi Katkılı Bitüm Kaplamaların Bazı Dayanım ve Dayanıklılık Özelliklerinin Araştırılması, Yüksek Lisans Tezi, Kahramanmaraş Sütçü İmam Üniversitesi, Kahramanmaraş, 2009.

[13] Abdul Rahman WMNW, Abdul Wahab AF. Green Pavement Using Recycled Polyethylene Terephthalate (PET) as Partial Fine Aggregate Replacement in Modified Asphalt, Procedia Engineering 2013; 53: 124-128.

[14] Ziari H, Kaliji A, Babagoli R. Laboratory evaluation of the effect of waste plastic bottle (PET) on rutting performance of hot mix asphalt mixtures, Petroleum Science and Technology 2016; 34(9): 819-823.

[15] Denghan Z, Modarres A. Evaluating the fatigue properties of hot mix asphalt reinforced by recycled PET fibers using 4point bending test, Construction and Building Materials 2017; 139: 384-393.

[16] Hassani A, Ganjıdoust H, Maghanaki A. Use of Plastic waste(Polyethylene terephthalate) in Asphalt Concrete Mixture as Aggregate Replacement, Waste Manage Res 2005; 23: 322-327. 
[17] Leng Z, Sreeram A, Padhan R, Tan Z. Value-added application of waste PET based additives in bituminous mixtures containing high percentage of reclaimed asphalt pavement (RAP), Journal of Cleaner Production 2018; 196: 615-625.

[18] El-Naga I, Ragab M. Benefits of utilization the recycle polyethylene terephthalate waste plastic materials as a modifier to asphalt mixtures, Construction and Building Materials 2019; 219: 81-90.

[19] Ameri M, Nasr D. Properties of asphalt modified with devulcanized polyethylene terephthalate, Petroleum Science and Technology 2016; 34(16): 1424-1430.

[20] Silva J, Lucena L, Rodrigues J, Carvalho M, Costa D. Use of Micronized Polyethylene Terephthalate (Pet) Waste in Asphalt Binder, Petroleum Science and Technology 2015; 33(15-16):1508-1515.

[21] Hoxha M. The Effects of Waste Polethylene Terepthalate (PET) on Asphalt Concrete, Master Thesis, Zirve University, Gaziantep, 2014.

[22] Jasso M, Hampl R, Vacin O, Bakos D, Stastn J, Zanzotto L. Rheology of Conventional Asphalt Modified with SBS, Elvaloy and Polyphosphoric acid, Fuel Proccessing Technology 2015; 140: 172-179.

[23] Polacco G, Filippi S, Merusi F, Stastna G. A Review of the Fundmentals of Polymer-Modified Asphalts: Asphalt/Polymer İnteractions and Principles of Compatibility, Advances in Colloid and Interface Science 2015; 224: 72112.

[24] Bulak E. Atık Polietilen Tereftalat (PET) ‘n Aminolizi ve Aminoliz Ürünlerinin Karakterizasyonu, Yüksek Lisans Tezi, İstanbul Üniversitesi, İstanbul, 2011.

[25] Pumphrey ME, Evaluation of Performance Graded Asphalt Binder Equipment and Testing Protocol, Graduate Theses, West Virginia University, Morgantown, 2004.

[26] McGennis RB, Anderson RM, Kennedy TW, Solaimanian M. Background of Superpave Asphalt Mixture Design and Analysis, Publication No. FHWA-SA-95-003, 1995.

[27] Geçkil T. Physical, Chemical, Microstructural and Rheological Properties of Reactive Terpolymer- Modified Bitumen, Materials 2019; 12(6): 921.

[28] Koral AF. Aynı Performans Seviyesine Sahip Bağlayıcılarla Hazırlanan Bitümlü Sıcak Karışımların Kalıcı Deformasyona Karşı Dayanımlarının ve Yorulma Ömürlerinin Karşılaştırılması, Yüksek Lisans Tezi, Fırat Üniversitesi, Elazı̆̆, 2012. 